Open Access

\title{
Erratum to: Multidisciplinary approach and anesthetic management of a surgical cancer patient with methylene tetrahydrofolate reductase deficiency: a case report and review of the literature
}

Marco Cascella $a^{1 *}$, Manuela Arcamone ${ }^{2}$, Emanuela Morelli ${ }^{2}$, Daniela Viscardi ${ }^{4}$, Viera Russo ${ }^{4}$, Silvia De Franciscis ${ }^{3}$, Andrea Belli ${ }^{3}$, Rosanna Accardo ${ }^{1}$, Domenico Caliendo ', Elena De Luca', Barbara Di Caprio ${ }^{1}$, Francesco Di Sauro', Giovanni Giannoni ${ }^{1}$, Carmine lermano ${ }^{1}$, Maria Maciariello ${ }^{1}$, Marcella Marracino ${ }^{1}$ and Arturo Cuomo ${ }^{1}$

The original version of this article [1] unfortunately contained a mistake. The presentation of the author names is incorrectly marked up and therefore it is presented incorrectly in the HTML version of this article. The corrected author list is given below:

Marco Cascella, Manuela Arcamone, Emanuela Morelli, Daniela Viscardi, Viera Russo, Silvia De Franciscis, Andrea Belli, Rosanna Accardo, Domenico Caliendo, Elena De Luca, Barbara Di Caprio, Francesco Di Sauro, Giovanni Giannoni, Carmine Iermano, Maria Maciariello, Marcella Marracino, Arturo Cuomo.

The original article was corrected accordingly.

\begin{abstract}
Author details
'Division of Anesthesia, Department of Anesthesia, Endoscopy and

Cardiology, Istituto Nazionale Tumori "Fondazione G. Pascale" - IRCSS, Naples, Italy. ${ }^{2}$ Division of Haematology-Oncology and Stem Cell Transplantation Unit, Istituto Nazionale Tumori "Fondazione G. Pascale" - IRCSS, Naples, Italy.

${ }^{3}$ Department of Abdominal Oncology Surgery, Istituto Nazionale Tumori

"Fondazione G. Pascale"- IRCSS, Naples, Italy. ${ }^{4}$ Department of Surgery,

Anesthesia, Emergency and Intensive Care, University of Naples "Federico II", Naples, Italy.
\end{abstract}

Published online: 17 September 2015

\section{Reference}

1. Cascella M, Arcamone M, Morelli E, Viscardi D, Russo V, De Franciscis S, et al. Multidisciplinary approach and anesthetic management of a surgical cancer patient with methylene tetrahydrofolate reductase deficiency: a case report and review of the literature. J Med Case Rep. 2015, 9:175.

\footnotetext{
* Correspondence: m.cascella@istitutotumori.na.it

'Division of Anesthesia, Department of Anesthesia, Endoscopy and Cardiology, Istituto Nazionale Tumori "Fondazione G. Pascale" - IRCSS, Naples,
} Italy

\section{Submit your next manuscript to BioMed Central and take full advantage of:}

- Convenient online submission

- Thorough peer review

- No space constraints or color figure charges

- Immediate publication on acceptance

- Inclusion in PubMed, CAS, Scopus and Google Scholar

- Research which is freely available for redistribution

Submit your manuscript at

www.biomedcentral.com/submit 